\title{
Alergia ao látex e a frutas em profissionais da área da saúde
}

\section{Latex and fruit allergy in health care workers}

Flávia Andréia MARIN ${ }^{1}$

Suely Prieto de Barros Almeida PERES 2

Maria do Carmo VENTURINI ${ }^{3}$

Rosane C. Melchiori FRANCISCO ${ }^{3}$

Antônio ZULIANI ${ }^{3}$

\section{R E S U M O}

\section{Introdução}

A alergia ao látex tornou-se um risco crescente aos indivíduos expostos, como os profissionais da área da saúde, tendo como agravo a associação com hipersensibilidade a vários alimentos, especialmente frutas.

\section{Objetivo}

Avaliar a freqüência de sensibilização ao látex e a frutas em profissionais da área da saúde.

\section{Métodos}

Foram avaliados 53 profissionais da saúde, 81,9\% do sexo feminino, aplicando-se questionário alergológico e testes cutâneos por puntura para alérgenos inaláveis, do látex e de frutas (mamão papaia, kiwi, abacate, banana, figo, tomate, noz).

\section{Resultados}

Dos 53 indivíduos estudados, 15 (28,5\%) eram alérgicos ao látex. A sensibilidade a frutas foi diagnosticada em $14(26,4 \%)$, dos quais 10 (18,8\%) apresentavam teste por puntura positivo para o látex; as frutas alergênicas mais freqüentes foram papaia $(80,0 \%)$, kiwi $(60,0 \%)$ e abacate $(50,0 \%)$.

\footnotetext{
1 Faculdade de Medicina, Universidade Estadual Paulista. Distrito de Rubião Júnior, s/n, 18600-970, Botucatu, SP, Brasil. Correspondência para/Correspondence to: F.A. MARIN.

2 Hospital de Reabilitação de Anomalias Craniofaciais, Universidade de São Paulo. Rua Dix, 1-35, 17043-220, Bauru, SP, Brasil.

3 Departamento de Pediatria, Faculdade de Medicina, Universidade Estadual Paulista, Botucatu.
} 


\section{Conclusão}

Estes achados demonstram a existência da alergia látex-fruta, como descrito na literatura, sendo de suma importância uma avaliação in vivo em profissionais da área de saúde, caracterizados como potencial grupo de risco.

Termos de indexação: hipersensibilidade ao látex, reatividade cruzada, profissionais de saúde.

\section{A B S T R A C T}

\section{Introduction}

Latex allergy is becoming an increasing risk to exposed individuals, such as the health care workers, and the simultaneous allergy to different types of food, particularly fruits is an aggravating circumstance.

\section{Objective}

To estimate the occurrence of hypersensitivity to both fruits and latex among health care workers.

\section{Methods}

Fifth-three health care workers, $81.9 \%$ of whom women, were studied by means of a specific questionnaire and through puncture cutaneous tests using allergens of latex and fruits (papaya, kiwi, avocado, banana, fig, tomato, nuts) as well as some potential inhalatory allergens.

\section{Results}

Of the 53 subjects studied, 15 (28.5\%) were allergic to the latex. Hypersensitivity to fruits was diagnosed in 14 (26.4\%) individuals, 10 of whom (18.8\%) presented a latex positive cutaneous test; papaya (80.0\%), kiwi (60.0\%) and avocado (50.0\%) were the most frequent allergenic fruits.

\section{Conclusion}

The present findings indicate a relatively high (18.8\%) occurrence of latex-fruit allergy, as already described in the literature. It is important to detect such a condition in health care workers, since they are a potential group at risk.

Index terms: latex hypersensibility, cross-reactivity, health occupations.

\section{N T R O D U Ç Ã O}

A alergia ao látex tornou-se um risco crescente aos indivíduos que estão constantemente expostos ${ }^{1,2}$, principalmente os profissionais da área de saúde ${ }^{3,4}$, devido ao aumento na prevalência de reações alérgicas mediadas por IgE específica para os alérgenos do látex, podendo, assim, caracterizar a alergia ao látex como uma doença ocupacional5.

A primeira reação alérgica ao látex foi descrita por Stem em $1927^{6}$ na Alemanha, mas somente Nutter em $1979^{7}$ relatou uma reação alérgica mediada por IgE específica para os alérgenos do látex. As reações alérgicas comumente observadas são urticária generalizada, rinite, conjuntivite, asma e anafilaxia ${ }^{8}$.

O principal alérgeno do látex é a heveína (Hev b 1), a qual constitui fator de alongamento da borracha e é um polipeptídio com peso molecular correspondente a $14,6 \mathrm{Kd}^{9-10}$. Outro importante alérgeno é a Hev b 3, proteína com peso molecular de $24 \mathrm{Kd}$. Estes polipeptídeos são responsáveis pela produção de lgE específica para o látex ${ }^{10,11}$.

Pode-se dizer que existe um vasto grupo de risco, incluindo, além de profissionais da área 
de saúde, pacientes submetidos freqüentemente a meios diagnósticos e terapêuticos ${ }^{12}$. Pacientes com espinha bífida são de alto risco, assim como aqueles com anomalias urogenitais congênitas. Em estudo de Cremer et al. (1998) ${ }^{13}$ sobre a prevalência de alergia ao látex em população com espinha bífida, demonstraram 40,5\% dos pacientes desenvolveram anticorpos IgE. Já Mace et al. (1998) ${ }^{4}$ encontraram uma incidência de $6,9 \%$ de reações alérgicas ao látex, em enfermeiras de centro cirúrgico, enquanto Aichane et al. (1997) ${ }^{14}$ constataram uma freqüência de 5,3\% em profissionais da saúde.

A alergia ao látex tem sido associada à alergia a alimentos, principalmente a frutas, ocorrendo pela presença de reações cruzadas entre os antígenos do látex e os contidos nestes alimentos $^{15,16}$.

Provavelmente estas reações cruzadas entre o látex e algumas frutas sejam decorrentes da existência de antígenos comuns, ou mesmo da presença de uma lisozima, polipetídeos que possuem funções enzimáticas (PM igual a 27Kd), similares às lisozimas das frutas ${ }^{17}$.

Delbourg et al. (1996) ${ }^{18}$ verificaram na banana a presença de mais de dez componentes alergênicos comuns ao látex, sendo considerados os principais alérgenos da banana os componentes com peso molecular variando de $33 \mathrm{Kd}$ a $37 \mathrm{Kd}$.

Chen et al. (1998) ${ }^{19}$, investigando a reatividade cruzada da heveína com proteínas do abacate, concluíram que a sensibilização depende dos epítopos da heveína, enquanto Sanchez-Monge (1999)20, identificaram em seus estudos dois alérgenos (34Kd e $32 \mathrm{Kd}$ ) responsáveis por mais de $50 \%$ das reações alérgicas à banana.

Em investigação de Garcia et al. (1998)21 sobre a prevalência de alergia ao látex em pacientes alérgicos a frutas (melão, pêssego, banana) e com história de reações ao látex, 85,9\% dos indivíduos avaliados apresentaram sensibilização imunológica a este último.

A freqüência de hipersensibilidade a alimentos em profissionais da área de saúde alérgicos ao látex é de $29,4 \%$, sendo especificamente observada em enfermeiras de centro cirúrgico 4 .

Considerando as evidências observadas pelos pesquisadores acima citados, torna-se pertinente uma investigação com estes grupos de risco. Neste intuito, este estudo objetivou avaliar a freqüência de sensibilização ao látex e a frutas em profissionais da área da saúde do Hospital de Reabilitação de Anomalias Craniofaciais (HRAC), da Universidade de São Paulo de Bauru.

\section{CASUÍSTICA E MÉTODOS}

A amostra constou de 53 indivíduos, abrangendo pessoal ativo do centro cirúrgico e do laboratório. O protocolo de pesquisa foi aprovado pela Comissão de Ética e Pesquisa do HRAC. Após esclarecimento prévio de todos os propósitos deste estudo, foram incluídos os indivíduos que aceitaram participar do protocolo e assinaram o termo de concordância, sendo ainda determinado como critério de inclusão a exposição ocupacional repetitiva aos alérgenos do látex, através do contato com luvas de borracha. O grupo amostral ficou assim caracterizado: 10 indivíduos do sexo masculino $(18,1 \%), 43$ do feminino $(81,9 \%)$, faixa etária variando de 22 a 56 anos, 7 $(13,2 \%)$ cirurgiões-dentistas, 7 (13,2\%) médicos-cirurgiões, 4 (7,5\%) enfermeiros, $6(11,4 \%)$ auxiliares de laboratório e 29 (54,7\%) auxiliares de enfermagem.

Todos os participantes foram submetidos a uma investigação sobre história de atopia, realizada por intermédio de um questionário alergológico. Foram utilizados parâmetros de identificação (sexo, idade, profissão, tempo de exposição ocupacional, número de cirurgias sofridas) e questões gerais sobre alergia dermatológica, respiratória (asma, rinite, e outras), alimentar e ao látex. Foram considerados atópicos os indivíduos com quadro clínico de asma, rinite alérgica, dermatite e eczema atópico, e com sensibilização cutânea a um ou mais alérgenos 
inaláveis ao teste cutâneo de hipersensibilidade imediata, e/ou à determinação dos níveis séricos de IgE total, efetuada pelo método de ensaio imunoenzimático por micropartículas (MEIA- Microparticles Enzyme Immunoassay), através do equipamento Imx (ABBOT Laboratories, Chicago, EUA).

Os testes alérgicos por puntura, realizados por técnico devidamente treinado (técnica de Pepys $(1975)^{22}$, modificada por Osterballe \& Weeke (1979) $)^{23}$, empregaram alérgenos inaláveis (1 $\mathrm{mg} / \mathrm{mL}$ - poeira doméstica, Dermatophagoides pteronyssinus, e Dermatophagoides farinae, IPI-ASAC Brasil), alérgenos alimentares $(2 \mathrm{mg} / \mathrm{mL}$, Allos-Clínica Brasil), incluindo mamão papaia, kiwi, figo, abacate, banana, tomate, noz, e alérgeno do látex (2mg/dL, Allos-Clínica Brasil). A histamina $(1 \mathrm{mg} / \mathrm{mL})$ foi utilizada como controle positivo o excipiente da solução fenolada a $2 \%$ foi usado como controle negativo.

Os critérios para leitura dos testes cutâneos de hipersensibilidade imediata foram previamente estabelecidos. A leitura foi efetuada 15 minutos após a realização dos testes e comparou-se o tamanho da pápula resultante com o tamanho das pápulas do excipiente e da histamina, considerando a reação positiva quando o diâmetro médio era superior a $3 \mathrm{~mm}$ ou maior que a pápula da histamina.

Posteriormente, dividiu-se a população estudada em dois grupos, sendo um composto pelos profissionais com teste alérgico por puntura positivo para o látex, compreendendo 15 indivíduos $(28,5 \%)$, e o outro constituído pelos profissionais com o mesmo teste negativo, abrangendo 38 indivíduos (71,5\%), a fim de verificar as possíveis associações, principalmente a sensibilização a alimentos, nos diferentes grupos.

O estudo da comparação do diagnóstico de alergia segundo os grupos de presença ou ausência, a partir das variáveis idade (anos), IgE total (UI/mL), tempo de exposição ocupacional em anos e número de cirurgias, foi realizado através do teste estatístico não paramétrico de Mann-Withney ${ }^{24}$.

\section{RES ULTADOS}

A atopia foi encontrada em 30 (56,6\%) profissionais estudados. Houve associação entre atopia e sensibilidade ao látex, pois observou-se predominância de atópicos (100,0\%) no grupo com teste cutâneo positivo para o látex.

Quanto aos níveis de IgE sérica total, ao número de cirurgias sofridas e ao tempo de exposição ocupacional destes profissionais, quando relacionados à presença de sensibilidade ao látex, notou-se que os valores de IgE total e o número de cirurgias foram significantemente maiores no grupo com teste cutâneo positivo ao látex, enquanto o tempo de exposição ocupacional não mostrou diferença estasticamente significante entre os grupos (ausência e presença de sensibilidade ao látex), (Tabela 1), indicando não ter havido relação com o tempo, mas ter ocorrido a sensibilização em virtude do contato repetitivo com os alérgenos do látex.

Tabela 1. Medidas descritivas das variáveis estudadas e resultados do teste de estatística da comparação dos grupos de diagnóstico (variação).

\begin{tabular}{lcccc}
\hline & \multicolumn{4}{c}{ Diagnóstico de alergia ao látex } \\
Variável & Ausente & Presente & Resultado do teste estatístico & $p$ \\
\hline IgE total & $22,05(3,50$ a 1110,36$)$ & $159,80(88,40$ a 514,40$)$ & 4,04 & $<0,0001$ \\
Exposição ocupacional & $8,50(1,00$ a 30,00$)$ & $6,00(2,00$ a 19,00$)$ & 0,14 & $>0,05$ \\
\hline Cirurgias & $2(0$ a 7$)$ & $1(0$ a 3$)$ & 2,03 & $<0,05$ \\
\hline
\end{tabular}

Teste estatístico não-paramétrico de Mann-Withney. 
As reações alérgicas ao contato com os produtos de borracha, principalmente luvas de látex, comumente mais relatadas foram dermatite de contato e eczema de contato, ocorrendo em 13 indivíduos, seguidos de rinoconjuntivite, presente em 6 indivíduos, urticária local e generalizada em 2, e angioedema em 1, totalizando 16 indivíduos, dos quais 11 foram caracterizados como alérgicos ao látex pelo teste cutâneo.

Reações alérgicas a frutas foram previamente descritas por quatro profissionais, um por kiwi (prurido oral), um por abacate (rinoconjuntivite), e dois por banana, relacionadas com manifestações clínicas como angioedema e urticária; somente um dos alérgicos a banana teve teste por puntura negativo para o látex, e todos apresentaram teste positivo para as frutas referenciadas como causa das reações alérgicas.

A associação entre a presença de sensibilidade a alimentos e a sensibilização ao látex foi sugerida pela presença de testes cutâneos positivos para alimentos em $14(26,4 \%)$ profissionais avaliados, dos quais $10(71,4 \%)$ tinham testes por puntura positivos para o látex.

Quanto à freqüência de sensibilidade aos alimentos avaliados nos indivíduos alérgicos ao látex, observou-se teste cutâneo por puntura positivo para papaia em $80 \%$ (8/10), kiwi em $60 \%$ (6/10), abacate em $50 \%$ (5/10), banana e noz em $40 \%$ (4/10), tomate em 30\% (3/10) e figo em 20\% (2/10), enquanto apenas quatro dos indivíduos não alérgicos ao látex tiveram sensibilidade a alimentos, dos quais dois apresentaram a tomate, um a figo e um a noz e banana.

\section{I S C U S S Ã O}

Os fatores compreendidos como de risco, envolvidos na ocorrência de reações alérgicas mediadas por lgE, vão desde uma história clínica que demonstra sensibilidade ao látex, como a existência de dermatite de contato, ou eczema nas mãos, ou, ainda, edema ou prurido após contato com produtos de borracha ${ }^{25,26}$, um quadro de alergia alimentar, principalmente a frutas 27,28 , até a atopia ${ }^{29}$. Aichane et al. (1997) ${ }^{14}$ observaram uma prevalência de $81 \%$ de atopia em indivíduos alérgicos ao látex.

Allmers et al. (1997) ${ }^{30}$ descreveram ocorrência de $22 \%$ de sensibilização de tipo I em profissionais da área de saúde, estando incluídos médicos, enfermeiras, dentistas, auxiliares odontológicos e de laboratório ${ }^{29,31,32}$

Segundo constataram Safadi et al. $(1996)^{31}$, a prevalência de hipersensibilidade ao látex é semelhante nos diferentes grupos de profissionais da saúde, e em uma população de dentistas $12 \%$ eram sensíveis aos antígenos do látex. Adicionalmente, Taylor \& Praditsuwan $(1996)^{5}$ descreveram que as manifestações alérgicas apresentadas por este grupo eram, freqüentemente, sintomas sistêmicos, eczema de mãos e dermatite de contato.

De acordo com este estudo, $28 \%$ dos profissionais da área de saúde avaliados por testes de puntura eram alérgicos ao látex, sendo todos atópicos e apresentando reações alérgicas como dermatite e eczema de contato. Estas manifestações são consideradas reações alérgicas do tipo IV e a possibilidade de polipeptídeos serem responsáveis por elas não foi criteriosamente investigada (Mourão \& Rosário Filho, 1995)24; no entanto, os sinais observados coincidem com os dados descritos na literatura.

Beezhold et al. (1996) observaram testes cutâneos positivos para abacate, batata, tomate, castanha e kiwi, em 33 dos 47 pacientes alérgicos ao látex por eles avaliados. Latasa et al. (1995) concluíram que, embora pacientes com alergia ao látex possam desenvolver múltipla sensibilização a frutas, as mais comuns são o abacate e a banana, seguidos da castanha e do melão.

Brehler et al. (1997)28 investigaram a ocorrência de reações cruzadas entre o látex e frutas (papaia, abacate, banana, castanha, figo, melão, kiwi, abacaxi, pêssego e tomate) e 
encontraram em 69,1\% dos pacientes alérgicos ao látex anticorpos lgE específicos para frutas; além disso, 42,5\% apresentaram manifestações clínicas após ingestão. Posteriormente, Moller et al. $(1998)^{33}$ demonstraram que quase todos os alérgenos do látex, abacate e banana, assim como dois alérgenos do kiwi (peso molecular $43 \mathrm{Kd}$ e 47Kd), compartilhavam epítopes IgE comuns.

Recentemente, Kim \& Hussain (1999) ${ }^{34}$ verificaram em 29 pacientes, dos 137 estudados com alergia ao látex diagnosticada por testes cutâneos e/ou testes in vitro, reações alérgicas a 15 diferentes tipos de alimentos, sendo banana, abacate, kiwi e tomate as frutas mais freqüentes. No presente estudo, dos 15 indivíduos alérgicos ao látex, $10(66,6 \%)$ eram alérgicos a duas frutas ou mais, sendo os principais a papaia, o kiwi e o abacate.

\section{O N CLUS Ã O}

Esta investigação evidencia uma nova problemática clínica com aspectos nutricionais, já que os achados confirmam a existência de um novo tipo de alergia, a alergia látex-fruta, ocasionada pela ocorrência de reações cruzadas entre os antígenos do látex e os de certos alimentos, especialmente de frutas, como sugerido na literatura e constatado neste estudo. É de suma importância a avaliação in vivo, por testes cutâneos de puntura com antígeno do látex e bateria de antígenos alimentares, de profissionais da saúde com exposição ocupacional repetitiva. Sugere-se ainda a realização de novas pesquisas, incluindo outros alimentos que possuem características semelhantes às daqueles estudados até o momento, a fim de prevenir estas manifestações alérgicas.

\section{REFER Ê N CIAS}

1. Yagami T, Sato M, Nakamura A, Komiyama T, Kitagawa K, Akasawa A, etal. Plant defense - related enzyme as latex antigens. J Allergy Clin Immunol 1998; 101(3):379-85.

2. Rueff F, Thomas P, Reissig G, Przybilla B. Natural rubber latex allergy in patients not intensely exposed. Allergy 1998; 53(4) :445-9.

3. Palczynski C, Walusiak J, Ruta U, Gorski P. Occupational allergy to latex life threatening reaction in health care workers. Report of three cases. Int J Occup Med Environ Health 1997; 10(3):297-301.

4. Mace SR, Sussman GL, Liss G, Stark DF, Beezhold $D$, Thompson $R$, et al. Latex allergy in operating room nurses. Ann Allergy Asthma Immunol 1998; 80(3):252-56.

5. Taylor JS, Praditsuwan P. Latex allergy review of 44 cases including outcome and frequent association with allergic hand eczema. Arch Dermatol 1996; 132(3):265-71.

6. Ebo DG, Stevens WJ, Bris CH, De Clerck LC. Latex-specific IgE, skin testing, and lymphocyte transformation to latex allergy. J Allergy Clin Immunol 1997; 100(5):618-23.

7. López S, Di Domênico MSDB, Castro FFM. Alergia ao látex. Rev Bras Alergia Imunopatol 1995; 18(4):126-29.

8. Latasa M, Dieguez I, Sanz MI, Parra A, Pajaron MJ, Oehling A. Fruit sensitization in patients with allergy to latex. J Invest Allergol Clin Immunol 1995; 5(2):97-102.

9. Chen Z, Van Kampen V, Raulf-Heimsoth M, Baur X. Allergenic and antigenic determinants of latex allergen Hev b1: peptide mapping of epitopes recognized by human, murine and rabbit antibodies. Clin Expe Allergy 1996; 26(4):406-15.

10. Yeang HY, Cheong KF, Sunderasan $E$, Hamzah $S$, Chew NP, Hamilton RG, et al. The 14.6 Kd rubber elongation factor ( $\mathrm{He} \mathrm{B} 1$ ) and $24 \mathrm{Kd}(\mathrm{Hev} \mathrm{b} \mathrm{3)}$ rubber particle proteins are recognized by $\mathrm{lg} E$ from patients with spina bifida and latex allergy. J Allergy Clin Immunol 1996; 98(3):628-29.

11. Alenius $H$, Kalkkinen $N$, Reunala $T$, Turjanmaa $T$, Palosuo T. The main IgE-binding epitope of a major latex allergen, prohevein, is present in its $\mathrm{N}$-terminal 
43-amino acid fragment, hevein. J Immunol 1996; 156(4):1618-625.

12. Burrow GH, Vincent KA, Krajbich Jl, Aiona MD. Latex allergy in non spina bitida patients: unfamiliar intra-operative anaphylaxis. Aust N Z J Surg 1998; 68(3):183-85.

13. Cremer K, Hoppe A, Korsch E, Kleine-Diepenbruck $U$, Blaker F. Natural rubber latex allergy: prevalence and risck factors in patients with spina bifida compared with atopic children and controls. Eur J Pediatr 1998; 157(1):13-6.

14. Aichane A, Bouayad Z, Outmani A, Afif N, Bahlaoui A. Latex allergy in a hospital setting: results of a study in Casablanca. Rev Maladies Resp 1997; 14(6):451-55.

15. Monreal P, Server MT, Torrens I, ESCODA JM. Hypersensitivity to fruits in latex allergic patients. Allergol Immunopathol 1996; 24(1):33-5.

16. Weiss SJ, Halsey JF. A nurse with anaphylaxis to stone fruits and latex sensitivity: potential diagnostic difficulties to consider. Ann Allergy Asthma Immunol 1996; 77(6):504-8.

17. Yagami T, Sato M, Nakamura A, Shono M. One of the rubber latex allergens is a lysozyme. J Allergy Clin Immunol 1995; 96(5):677-86.

18. Delbourg MF, Guilloux L, Moneret-Vautrin DA, Ville G. Hypersensitivity to banana in latex-allergic patients. Identification of two major banana allergens of 33 and $37 \mathrm{kd}$. Ann Allergy Asthma Immunol 1996; 76(4):321-26.

19. Chen Z, Posh A, Cremer R, Raulf-Heimsoth M, Baur $X$. Identification of hevein (Hev b 6.02) in Hevea latex as major cross-reacting allerg with avocado fruit in patients with latex allergy. J Allergy Clin Immunol 1998; 108(3):476-81.

20. Sanchez-Monge R. Isolation and characterization of major banana allergens: identification as fruit class I chitinases. Clin Exp Allergy 1999; 29(5): 673-80.

21. Garcia JCO, Moyano JC, Alvarez M, Bellido J. Latex allergy in fruit-allergic patients. Allergy 1998; 53(5):532-36.

22. Pepys J. Skin testing. Br Med J 1975; 14:412-15.
23. Osterballe O, Weeke B. A new lancet for skin prick testing. Allergy 1979; 34:209-12.

24. Siegel S, Castellan Jr, NJ. Nonparametric statistics for the behavioral sciences. 2nd ed. New York: McGraw-Hill; 1988. p.312.

25. Mourão EMM, Rosário Filho NA. Alergia ao látex. In: Negreiros B, Ungier C. Alergol Clín. São Paulo: Atheneu; 1995. p.389-97.

26. Geller M, Paiva TCB de Geller P. Alergia ao látex mediada por IgE em centro cirúrgico. Rev Bras Alerg Imunopatol 1997; 20(5):166-8.

27. Beezhold DH, Sussman GL, Liss GM, Chang NS. Latex allergy can induce clinical reactions to specific foods. Clin Expe Allergy 1996; 26(4):416-22.

28. Brehler R, Theissen U, Mohr C, Luger T. "Latex-fruit syndrome": frequency of cross - reacting $\lg \mathrm{E}$ antibodies. Allergy 1997; 52(4):404-10.

29. Field EA. Atopy and other risk factors for UK dentists reporting an adverse reaction to latex gloves. Contact Dermatitis 1998; 38(3):132-6.

30. Allmers $H$, Huber $H$, Wirtz C, Kirchner B, Raulf-Heimsoth M, Baur X. Exposure testing with powdered gloves in 60 health care workers with latex allergy. Dtsch Med Wochenschr 1997; 122(43):1308-12

31. Safadi GS, Safadi TJ, Terezhalmy JS, Battisto JR, Melton AL. Latex hypersensitivity: its prevalence among dental professionals. J Am Dent Assoc 1996; 127(1):83-8.

32. Camacho Ibarra VC, Lopez Garcia Al, Galindo Garcia JA, Paz Martinez D, Papaqui Tapia JS. Prevalence of latex hypersensitivity among medical personnel. Rev Alerg Méx; 1997 44(6):150-2.

33. Moller M, Kayama M, Vieluf D, Paschke A, Steinhart $H$. Determination and characterization of cross reacting allergens in latex, avocado, banana, and kiwi fruit. Allergy 1998; 53(3):289-96.

34. Kim KT, Hussain $\mathrm{H}$. Prevalence of food allergy in 137 latex-allergic patients. Allergy Asthma Proc 1999; 20(2):95-7.

Recebido para publicação em 16 de agosto de 2001 e aceito em 27 de fevereiro de 2003. 